\title{
Effect of asbestos on lipid peroxidation in the red cells
}

\author{
SILVIA GABOR and ZOE ANCA \\ Institute of Public Health and Medical Research, Str. Pasteur 6, Cluj, Roumania
}

\begin{abstract}
Gabor, Silvia and Anca, Zoe (1975). British Journal of Industrial Medicine, 32, 39-41. Effect of asbestos on lipid peroxidation in the red cells. In vitro exposure of red cells to five International Union against Cancer (UICC) standard reference asbestos samples resulted in an increase of thiobarbituric acid substances. Chrysotiles developed the largest amounts of lipid peroxides, followed by anthophyllite, amosite, and crocidolite in decreasing order. Compared with the control samples, erythrocytes free of dusts, all types of the asbestos examined disclosed significant differences. The results obtained provide support for the cytotoxic potential of amosite and crocidolite and, on the other hand, suggest that a lipid peroxidation of unsaturated fatty acids may be involved in the mechanism(s) of membranedamaging effects of asbestos dusts.
\end{abstract}

Several reports indicate that asbestos dusts alter the permeability of the cellular membrane. However, the results obtained by haemolytic tests and macrophage cultures are somewhat contradictory. Secchi and Rezzonico (1968), Szentei (1969), Harington, Miller, and McNab (1971), and Schnitzer and Pundsack (1970) have demonstrated a strong haemolytic activity of chrysotile asbestos compared with amphibole asbestos, amosite, and crocidolite. It has been suggested that the action of asbestos dusts is mediated through membrane and cytoplasmic enzymes. Secchi and Rezzonico (1968) related the strong lytic activity of chrysotile asbestos to its adsorptive capacity for the erythrocyte membrane enzyme acetylcholinesterase. Koshi, Hayashi, and Sakabe (1968), by measuring acid phosphatase and production of lactic acid in macrophages, showed the different toxic effects of asbestos samples of different origin. Beck, Holt, and Manojlovic (1972) did not observe a depression of the lactic acid in chrysotiletreated macrophages but there was an increased number of cells with erythrosin and higher activity of the cytoplasmic enzyme lactate dehydrogenase. However, Parazzi, Pernis, Secchi, and Vigliani (1968) found a depression in the production of enzymes in crocidolite and chrysotile incubated macrophage cultures. A sample of crocidolite was more toxic than chrysotile. In an earlier study performed by the same team (Pernis, Vigliani, Marchisic, and Zanardi, 1966), crocidolite was found to be non-toxic. By investigating the effects of dusts on peritoneal macrophages by three different biochemical methods (TTC-test, nigrosine, and oxygen consumption), Robock and Klosterkötter (1973) concluded that chrysotile had the stronger cytotoxic action compared to crocidolite. In Allison's (1971) experiments chrysotile was found to be the most cytotoxic, followed by crocidolite, amosite, and anthophyllite.

The variability of the experimental results can be explained by the existing great differences between the asbestos samples in composition and in their mineralogical, physical, and chemical characteristics. The use of UICC standard samples of asbestos is therefore recommended for experimental purposes (Timbrell, Gibson, and Webster, 1968).

In spite of the different opinions regarding the biological response of the various types of asbestos dusts, there is general agreement concerning their action on membrane permeability. As regards the biochemical reactions which might affect membrane stability, the damaging effects of lipid peroxides 
induced by certain noxious agents is a well recognized phenomenon (Recknagel and Goshal Amiya, 1966; Goldstein, Lodi, Collison, and Balchum, 1969; Hanstein and Hatefi, 1970; Wills, 1971; Chvapil, Ryan, and Zukoski, 1972; Bidlak and Tappel, 1973).

In our previous work (Gabor, Frits, Anca, and Zugravu, 1971; Gabor and Anca, 1974) with silica dusts we noted an increased rate of lipid peroxidation in vivo in the silicotic lung and in in vitro dusttreated red cells.

Taking these findings as a starting point, the experiment reported here aimed to determine the lipid peroxides occurring in erythrocytes exposed to asbestos dusts.

\section{Materials and methods}

Five UICC standard reference asbestos samples were used-two chrysotiles (A and B) of the serpentine group, and three types of the amphibole group, an amosite, a crocidolite, and an anthophyllite.

\section{Preparation of erythrocyte suspension}

Human erythrocytes were used. They were collected from healthy donors in citrate-isotonic saline solution. The plasma and buffy coat were removed after centrifugation at $1500 \mathrm{rev} / \mathrm{min}$. The red cells were washed four times with veronal-buffered saline ( $\mathrm{pH} 7 \cdot 4)$.

Preparation of asbestos samples

The samples of each asbestos dust were suspended in veronal-buffered saline ( $\mathrm{pH} 7 \cdot 4)$ to which a surface wetting substance (RBS 25$)$ had been added $(0 \cdot 1 \mathrm{ml})$.

Haemolysis test

Mixtures of $1 \mathrm{ml}$ of dust suspension (13 $\mathrm{mg}$ asbestos) and
$6 \mathrm{ml} 8 \%$ erythrocyte suspension were incubated for one hour in a $37^{\circ} \mathrm{C}$ water-bath. During the incubation period the content of the test-tubes was gently shaken at 10minute intervals. In the control samples (consisting of $6 \mathrm{ml} 8 \%$ erythrocyte suspension and $0.1 \mathrm{ml}$ RBS 25) complete haemolysis was obtained by freezing and thawing.

\section{Lipid peroxidation assay}

Lipid peroxides were determined by the thiobarbituric acid method (TBA) which provided a measure of a malonaldehyde, one of the major products resulting from the peroxidation of unsaturated fatty acids (Wills, 1971). Aliquots of $6 \mathrm{ml}$ incubation mixtures were treated with $3 \mathrm{ml} 20 \%$ trichloracetic acid and centrifuged for 10 minutes. A proportion of supernatant was added to an equal volume of aqueous $0.76 \%$ 2-thiobarbituric acid, then heated in a boiling water-bath for 10 minutes and cooled to room termperature. The coloured product was extracted with $4 \mathrm{ml}$ cyclohexanone and measured in a spectrophotometer at $535 \mu \mathrm{m}$. The results were expressed as extinction values. In order to ascertain whether the lipid peroxides (i.e., the malonaldehyde formation) were intimately associated with erythrocyte membrane (haemoglobin-free erythrocyte ghosts), or if they were released into the supernatant, the erythrocyte suspension was centrifuged and the lipid peroxides were determined separately in the supernatant solution and in the three times washed precipitate.

\section{Results and discussion}

Data showing the action of asbestos dusts on the lipid peroxidation of erythrocytes are given in the Table.

As seen in the Table, different types of asbestos dusts developed an increased rate of lipid peroxides

\section{TABLE}

Lipid Peroxidation of the Red Blood Cells by Different Asbestos Dusts (UICC Samples)

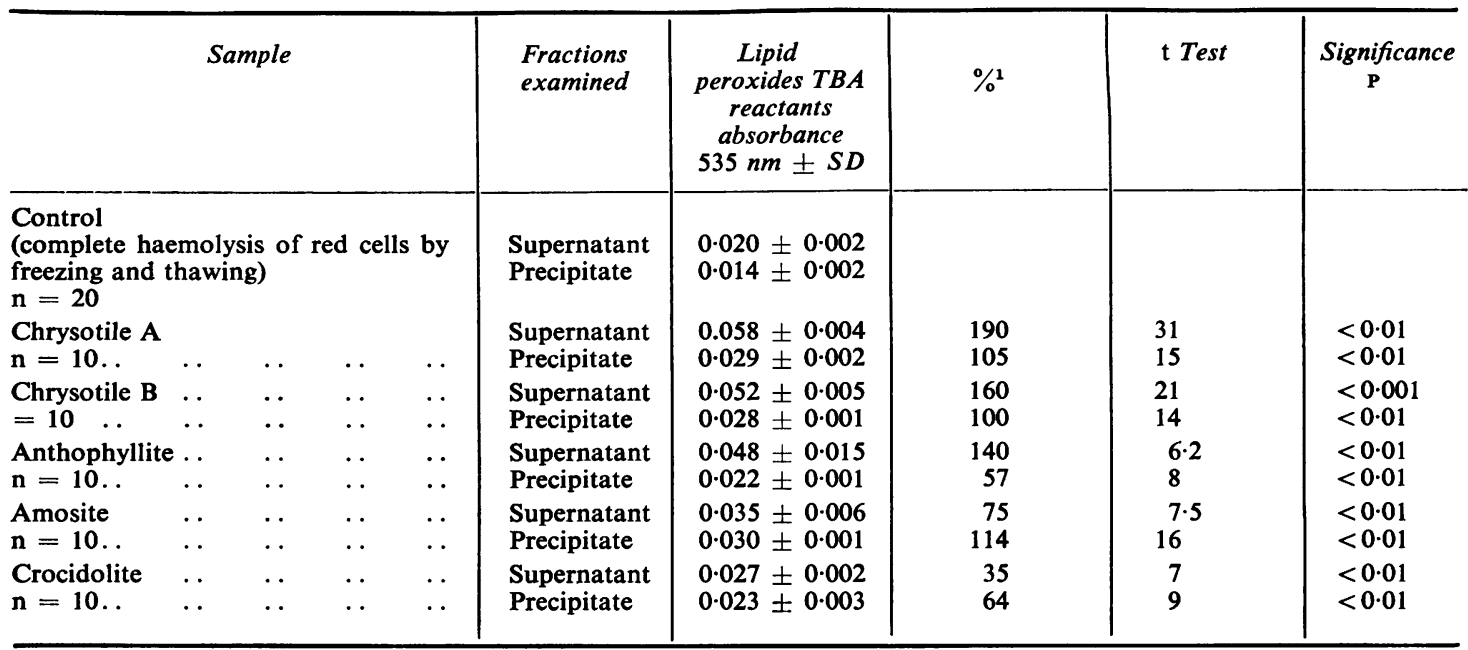

$\mathbf{n}=$ number of experiments

'Percentage increase related to the control sample 
in the red blood cells, either in the supernatant or in the haemoglobin-free erythrocyte precipitates, compared to the control sample (complete haemolysis without dust). The highest levels of lipid peroxides were formed in erythrocytes incubated with serpentine asbestos (chrysotile A and B). Amphibole asbestos, anthophyllite, notably amosite and crocidolite, induced lipid peroxidation to a lesser degree. Our findings agree with the results reported by other authors (Harington et al., 1971; Robock and Klosterkötter, 1973) regarding the most effective cytotoxic action of serpentine asbestos-chrysotiles. When we consider the relation between the percentage of lipid peroxide levels recovered in the supernatant and precipitate (haemoglobin-free erythrocyte ghosts) and the control samples, the fact that amosite and crocidolite have developed an increased rate of lipid peroxides in the precipitate, i.e., in the erythrocyte membrane, is of particular interest. As can be seen in the Table, the percentage of increasing lipid peroxides was 114 for amosite in the precipitate compared with $75 \%$ in the supernatant; for crocidolite the figures were $64 \%$ in the precipitate and $35 \%$ in the supernatant. This high rate of lipid peroxidation closely associated with the membrane shows that amosite and crocidolite are not entirely devoid of cytotoxic potential though they have been considered inactive as lytic agents against erythrocytes.

From the results presented here we may conclude that one of the various mechanisms by which asbestos dusts might exert their cytotoxic action includes lipid peroxidation. This conclusion is also supported by Allison's (1971) previous observations regarding the development of brown pigmented autofluorescent granules in cytoplasm in asbestostreated cells, suggesting an involvement of lipid peroxidation.

We are grateful to Dr. V. Timbrell, of the Pneumoconiosis Research Unit, Llandough Hospital, Penarth, for making available the UICC standard asbestos reference samples.

\section{References}

Allison, A. C. (1971). Effects of silica and asbestos on cells in culture. In Inhaled Particles, III, Vol. 1, edited by W. H. Walton, pp. 437-441. Unwin, London.

Beck, F. G., Holt, P. F., and Manojlovic, N. (1972). Comparison of effects on macrophage cultures of glass-fibre, glass-powder and chrysotile asbestos. British Journal of Industrial Medicine, 29, 280-286.
Bidlak, W. R. and Tappel, A. L. (1973). Damage to microsomal membrane by lipid peroxidation. Lipids, 8, 4, 177-182.

Chvapil, M., Ryan, J. N., and Zukoski, Ch. F. (1972). Effect of zinc on lipid peroxidation in liver microsomes and mitochondria. Proceedings of the Society of Experimental Biology and Medicine, 141, 1, 150-152.

Gabor, S. and Anca, Z. (1974). Effect of silica on lipid peroxidation in the red cells. International Archives of Occupational Health, 32, 327-332.

- Frits, T., Anca, Z., and Zugravu, E. (1971). Taux des lipoperoxides dans les poumons et le myocarde droit dans la silicose expérimentale, chez le rat. Archives des Maladies Professionnelles, de Médecine, du Travail et de Sécurité Sociale, 32, 553-558.

Goldstein, B. D., Lodi, C., Collison, C., and Balchum, O. J. (1969). Ozone and lipid peroxidation. Archives of Environmental Health, 18, 631-635.

Hanstein, W. G. and Hatefi, Y. (1970). Lipid oxidation in biological membranes. Archives of Biochemistry and Biophysics, 138, 87-95.

Harington, J. S., Miller, K., and Macnab, G. (1971). Hemolysis by asbestos. Environmental Research, 4, 95-117.

Koshi, K., Hayashi, H., and Sakabe, H. (1968). Cell toxicity and hemolytic action of asbestos dusts. Industrial Health, 6, 69-79.

Parazzi, E., Pernis, B., Secchi, G. C., and Vigliani, E. C. (1968). Studies on 'in vitro' cytotoxicity of asbestos dusts. Medicina del Lavoro, 59, 561-576.

Pernis, B., Vigliani, E. C., Marchisic, M. A., and Zanardi, S. (1966). Observations on the effect of asbestos on cells 'in vitro'. Medicina del Lavoro, 57, 721-729.

Recknagel, R. O. and Goshal Amiya, K. (1966). New data on the question of lipoperoxidation in carbon tetrachloride poisoning. Experimental and Molecular Pathology, 5, 108-117.

Robock, K. and Klosterkötter, W. (1973). Untersuchungen über die Zytotoxizität von Asbest-Stäuben. Staub-Reinhaltung der Luft, 33, 279-282.

Schnitzer, R. J. and Pundsack, F. L. (1970). Asbestos hemolysis. Environmental Research, 3, 1-13.

Secchi, G. C. and Rezzonico, A. (1968). Hemolytic activity of asbestos dusts. Medicina del Lavoro, 59, 1-5.

Szentei, F. (1969). Hämolyseversuche mit Asbest. Zentralblatt für Bakteriologie, pt. 1, Referate 215, 508.

Timbrell, V., Gibson, J. C., and Webster, I. (1968). UICC standard reference samples of asbestos. International Journal of Cancer, 3, 406-408.

Wills, E. D. (1971). Effects of lipid peroxidation on membrane-bound enzymes of the endoplasmic reticulum. Biochemical Journal, 123, 983-991.

Received for publication 27 February 1974

Accepted for publication 8 August 1974 